\title{
A computational tool for designing BWRO systems with spiral wound modules
}

\author{
A. Ruiz-García ${ }^{\mathrm{a}, 1, *}$, I. Nuez ${ }^{\mathrm{b}, * *}$ \\ ${ }^{a}$ Department of Mechanical Engineering, University of Las Palmas de Gran Canaria. Edificio de Ingenierías, Campus Universitario de Tafira, \\ 35017 Las Palmas de Gran Canaria, Spain \\ ${ }^{b}$ Department of Electronic and Automatic Engineering, University of Las Palmas de Gran Canaria. Edificio de Ingenierías, Campus Universitario \\ de Tafira, 35017 Las Palmas de Gran Canaria, Spain
}

\begin{abstract}
Deficiencies in commercial programs for the design of RO systems motivate the development of new ones that allow a flexible design and more realistic operating conditions for this type of systems. This work presents a computational tool for designing BWRO systems with spiral-wound modules. This algorithm has advantages over commercial software supplied by membrane manufacturers (such as ROSA, IMSDesign or $\mathrm{Q}^{+}$Projection Software), whose trialand-error approach results in a waste of time for the designer. The proposed program has an additional boundary condition: to achieve the maximum flux recovery without scaling due to the precipitation of sparingly soluble mineral salts (e.g., silica $\left(\mathrm{SiO}_{2}\right)$, calcium carbonate $\left(\mathrm{CaCO}_{3}\right)$, calcium sulphate dihydrate (denoted simply as $\left.\mathrm{CaSO}_{4}\right)$, barium sulphate $\left(\mathrm{BaSO}_{4}\right)$, strontium sulphate $\left(\mathrm{SrSO}_{4}\right)$ and calcium fluoride $\left.\left(\mathrm{CaF}_{2}\right)\right)$. The designer's liberty to change the constrains established by membrane manufacturers provides the user with a desired safety margin and more flexibility. A range of 1 to 8 elements in each pressure vessel, 1 to 3 stages and the possibility of inter-stage pumping are taken into consideration. The results are displayed in a multi-filterable and sortable table. This allows the user to see all possible solutions and choose the most appropriate. The algorithm also has a predictive model of the performance of RO systems, providing an estimation of the performance of the selected RO system in the long term. The program has been validated using the experimental data of four full-scale BWRO desalination plants, proving that the proposed program is closer to actual data than the computational tool supplied by the manufacturer.
\end{abstract}

Keywords: Brackish water, RO system design, Reverse osmosis, Spiral-wound modules, Computational tool.

\section{Introduction}

Nowadays, reverse osmosis (RO) is on the lead of seawater and brackish water desalination technology. This has led to numerous attempts to improve its technology in terms of new materials [1-3], the design of the spiral-wound element [4-7] and of the process itself [8-11]. Usually, the computational tools available for the design of RO systems do not provide enough information for an optimal result.

Deficiencies in commercial programs for the design of RO systems motivate the development of new ones that allow a flexible design and more realistic operating

\footnotetext{
*Alejandro Ruiz-García

** Ignacio de la Nuez-Pestana

Email addresses: alejandro.ruiz@ulpgc.es (A.

Ruiz-García ), ignacio.nuez@ulpgc.es (I. Nuez )

${ }^{1}$ Tel. 34928451888
}

Preprint submitted to Desalination conditions for this type of systems. Commercial software (such as ROSA, IMSDesign or $\mathrm{Q}^{+}$Projection Software) emulate systems already introduced by the user, forcing them to test different arrangements to find a system with the desired operating conditions. Besides, commercial packages do not allow the establishment of new constrains, nor changing the ones established by the membrane manufacturer to widen the safety margin.

Many authors have proposed procedures to optimize the design of RO systems. A. Villafafila et. al. [12] proposed the optimization of an objective function that considered the number of tubes, flux recovery and the specific energy consumption $(S E C)$ for both seawater and brackish water. These authors used parameters for tubular membrane configuration and energy recovery devices. They only considered constraints concerning the number of pressure vessels (PV), values of pressure, membrane diameter and feed flux. Afterwards and in 


\begin{tabular}{|c|c|c|c|}
\hline \multicolumn{4}{|c|}{ Nomenclature } \\
\hline \multicolumn{2}{|c|}{ Acronyms } & $T$ & Temperature $\left({ }^{\circ} \mathrm{C}\right)$ \\
\hline \multirow[t]{2}{*}{$A$} & \multirow{2}{*}{$\begin{array}{l}\text { Water permeability coefficient }\left(\mathrm{m}^{3} \mathrm{~m}^{-2} \mathrm{~d}^{-1}\right. \\
\left.\mathrm{kg}^{-1} \mathrm{~cm}^{2}\right)\end{array}$} & $T C F$ & Temperature correction factor \\
\hline & & $T D S$ & Total dissolved solids $\left(\mathrm{mg} \mathrm{l}^{-1}\right)$ \\
\hline$B$ & Ion permeability coefficient $\left(\mathrm{m} \mathrm{d}^{-1}\right)$ & Y & Fraction recovery \\
\hline$C$ & Concentration $\left(\mathrm{mg}^{-1}\right)$ & \multicolumn{2}{|c|}{ Greek letters } \\
\hline$D$ & Solute diffusivity $\left(\mathrm{m}^{2} \mathrm{~s}^{-1}\right)$ & $\beta$ & Angle between crossing filaments \\
\hline$d$ & Filament diameter (m) & $\Delta \pi$ & Osmotic pressure gradient $\left(\mathrm{kg} \mathrm{cm}^{-2}\right)$ \\
\hline$d_{\mathrm{h}}$ & Hydraulic diameter $(\mathrm{m})$ & $\Delta C$ & Concentration gradient $\left(\mathrm{mg}^{-1}\right)$ \\
\hline$F F$ & Flow factor & $\Delta p$ & Pressure gradient $\left(\mathrm{kg} \mathrm{cm}^{-2}\right)$ \\
\hline$J$ & Flow per unit area $\left(\mathrm{m}^{3} \mathrm{~m}^{-2} \mathrm{~d}\right)$ & $\eta$ & Dynamic viscosity $\left(\mathrm{kg} \mathrm{m}^{-1} \mathrm{~s}\right)$ \\
\hline$k$ & Mass transfer coefficient & $\lambda$ & Friction factor \\
\hline$K_{\lambda}$ & Additional pressure losses factor & $v$ & Velocity $\left(\mathrm{m} \mathrm{s}^{-1}\right)$ \\
\hline$L$ & Cylinder spacing (m) & $\pi$ & Osmotic pressure $\left(\mathrm{kg} \mathrm{cm}^{-2}\right)$ \\
\hline$m$ & Molal concentration $\left(\mathrm{mol} \mathrm{kg}^{-1}\right)$ & $\rho$ & Density $\left(\mathrm{kg} \mathrm{m}^{-3}\right)$ \\
\hline$N D P$ & Net driven pressure $\left(\mathrm{kg} \mathrm{cm}^{-2}\right)$ & \multicolumn{2}{|c|}{ Subscripts } \\
\hline$P$ & Solute pass (\%) & av & Average \\
\hline$p$ & Pressure $\left(\mathrm{kg} \mathrm{cm}^{-2}\right)$ & $\mathrm{b}$ & Brine \\
\hline$P F$ & Polarization factor & $\mathrm{f}$ & Feed \\
\hline$Q$ & Flow $\left(\mathrm{m}^{3} \mathrm{~d}^{-1}\right)$ & $\mathrm{i}$ & Membrane element i \\
\hline$R$ & Flow recovery $(\%)$ & $\mathrm{j}$ & Ion $\mathrm{j}$ \\
\hline$R e$ & Reynolds number & $\max$ & Maximum \\
\hline$S_{m}$ & Membrane surface $\left(\mathrm{m}^{2}\right)$ & $\min$ & Minimum \\
\hline$S c$ & Schmidt number & $\mathrm{m}$ & Membrane \\
\hline$S D I$ & Silt density index & $\mathrm{p}$ & Permeate \\
\hline$S E C$ & Specific energy consumption $\left(\mathrm{kW} \mathrm{h} \mathrm{m}^{-3}\right)$ & s & Solute \\
\hline$S h$ & Sherwood number & & \\
\hline
\end{tabular}

the same vein, M. Barello et. al. [13] would provide experimental data, focusing on water and salt permeability coefficients for this type of membrane element.

M. G. Marcovecchio et. al. [14] optimized the design of RO systems for seawater with up to two-stage arrangements. In this case, hollow fiber membranes and energy recovery systems were considered, lowering the cost function. No constraints or experimental data were provided.
Similarly V. Geraldes et. al. [15] optimized the design of a two-stage seawater RO system but, in this case, they considered spiral-wound membranes, the most common in this field. The authors used experimental data to identify certain parameters in the design equations. This module optimizes the pressure and feed flux for different water recovery rates.

C. Guria et. al. [16] presented a project for seawater, using spiral-wound and tubular modules. Apart from the constraints established by the manufacturers, they 
included the quality of the permeate, establishing as objective functions the maximization of the permeate throughput, and the minimization of desalination costs and permeate concentration. This work was carried out with no experimental data, and focused on the comparison of different multi-objective optimization algorithms.

An optimum design of RO systems under different feed concentration and permeate specification was developed by Yan-Yue Lu et. al. [17]. This method allows the integration of different membrane modules in the PV, as well as different inter-stage booster pumps and energy recovery devices.

F. Vince et. al. [18] developed a multi-objective optimization method for the design of this type of systems, where no constraints were added to the manufacturer's and no experimental data was provided. They proposed the optimization of SEC and permeate flux in relation to the cost of the permeate. Spiral-wound membranes for seawater and brackish water, energy recovery devices and up to two stages with inter-stage booster pumps were considered.

K. M. Sassi et. al. [19] proposed an optimization of the operation of the $\mathrm{RO}$ desalination process utilizing spiral-wound membranes modules with membrane fouling. The $S E C$ at fixed permeate flow rate and quality was minimized. The study used brackish water and Abbas et al.'s [20] model for predicting performance, depending only on their operating time.

In their optimization method, Y. Du et. al. [21] considered both seawater and brackish water RO desalination systems with spiral-wound modules. The only constraints concerned flux, and were established by the manufacturer. They considered up to two-stage systems with isobaric chambers as energy recovery devices. Costs according to SEC and water recovery were reduced. In a later work [22] they included different energy recovery devices for seawater. Aiming to improve the previous works, they carried out a third one [23], considering the possibility of an RO system with different steps, and with inter-step partial flux. $\mathrm{H}$. Kotb et. al. [24], proposed a similar work, considering seawater and up to three stages, apart from inter-stage booster pumps between them.

Ali Altaee [25] developed a computational model for estimating RO system design and performance. He only considered one-stage arrangements and sodium chlo- ride solutions, which resembled seawater closelythis study simulated different feedwater concentrations between $35 \mathrm{~g} \mathrm{l}^{-1}$ and $38 \mathrm{~g} \mathrm{l}^{-1}$. Only the manufacturer's data, and no experimental data of his own, was used. The user is unable to establish new constraints or to optimize system. The coefficient used for the prediction of performance is given by the manufacturer, with no experimental corroboration. Finally, he compares the proposed model with ROSA, and obtains similar results for the two.

E. Ruiz-Saavedra et. al. [26, 27] developed a design method of BWRO systems that considered the inorganic composition of the feedwater when establishing the operating conditions. However, these values resulted from practical experience, and could not be modified by the user. There is another limitation to this method: its possible arrangements. It allows for a maximum of 6 elements in each PV for one-stage modules. For two-stage modules, the only possibilities were $2: 1$ and 3:2 arrangements with 6 elements in each PV. This method offers solutions to maximize the system recovery rate with the minimum number of membranes, except for two-stage systems, for reasons explained above. This work did not regard the optimization of RO systems considering $S E C$. This algorithm, unlike the ones proposed by the previous authors, offered long-term operation data (5 years), with which to draw a comparison between the results obtained with the five years of practical experience, granting it a high level of reliability.

June-Seok Choi et. al. [28] centered his work around the optimization of two-step seawater RO systems. They considered spiral-wound membranes, but did not provide experimental work. Apart from the maximization of overall recovery, and minimization of $S E C$, this system minimized boron concentration in permeate (being this constraint the main novelty in the optimization process).

The aim of this work was to develop an algorithm design for BWRO systems. This computational tool enables greater flexibility regarding design parameters lacking in commercial software supplied by membrane manufacturers. Furthermore, it offers diverse optimum solutions in a direct manner, depending on the necessities and constraints established. In order to validate the program, experimental data compiled from 80,000 operating hours of a BWRO desalination plant was used to set the water and ionic permeability coefficients for the membrane element BW30-400 [29]. 
A predictive model for the long-term performance of $\mathrm{RO}$ systems proposed in another paper by the authors was implemented [30].

\section{Material and methods}

\subsection{Equations for water and solute transport}

Solution-diffusion $[31,32]$ was the method of transport used, since it is the most widely accepted and provides results close to the real behavior of these systems. Transport equations have used mean values of membrane elements, and pressure drop in the permeate as well as temperature changes along the RO systems have been disregarded.

The transport equations used are the following:

$$
Q_{\mathrm{p}}=A \cdot(\Delta p-\Delta \pi) \cdot S_{\mathrm{m}}
$$

where $Q_{\mathrm{p}}$ is the permeate flow, $A$ is the membrane permeability coefficient, $(\Delta p-\Delta \pi)$ is the net driven pressure $(N D P)$ and $S_{\mathrm{m}}$ is the membrane area.

Solute transport equation:

$$
Q_{\mathrm{s}}=B \cdot \Delta C \cdot S_{\mathrm{m}}
$$

where $Q_{\mathrm{s}}$ is the solute flow through the membrane, $B$ is the solute permeability coefficient of the membrane, $\Delta C$ is the concentration gradient of solute on either side of the membrane.

The behavior of membranes within the same element is not the same. Neither is that of the elements, for the manufacturing process is not perfect. From the point of view of design, it seems convenient to assume mean values for elements. Commercial software do this, and so will we in this work. Apart from using mean values, pressure decrease in the permeate as well as temperature changes along the RO system have been disregarded. Besides, the following have been taken into consideration:

- Negligible pressure decrease in the permeate side.

- Constant pressure drop along the membrane elements in the feed-brine side $\left(\Delta p_{\mathrm{fb}_{\mathrm{i}}}\right)$.

- Constant permeate flow per membrane element $\left(Q_{\mathrm{p}_{\mathrm{i}}}\right)$.

- Feed-brine concentration $\left(C_{\mathrm{fb}_{\mathrm{i}}}\right)$, concentration on membrane surface $\left(C_{\mathrm{m}_{\mathrm{i}}}\right)$ and feed pressure $\left(p_{\mathrm{f}_{\mathrm{i}}}\right)$ are constants in the membranes elements.
The coefficient $A$ (Eq. 1) depends on three variables: osmotic pressure on the membrane surface $\left(\pi_{\mathrm{m}_{\mathrm{i}}}\right)$, temperature, and flow factor related to fouling and operating time [33].

$$
A=A\left(A_{0}, \pi_{\mathrm{m}_{\mathrm{i}}}\right) \cdot T C F \cdot F F
$$

where $A_{0}$ is the initial water permeability coefficient.

$$
\pi_{\mathrm{m}_{\mathrm{i}}}=\pi_{\mathrm{f}_{\mathrm{i}}} \cdot \frac{C_{\mathrm{fb}_{\mathrm{i}}}}{C_{\mathrm{f}_{\mathrm{i}}}} \cdot P F_{\mathrm{i}}
$$

where $\pi_{\mathrm{f}_{\mathrm{i}}}$ is the osmotic pressure of feedwater and $P F_{\mathrm{i}}$ is the concentration polarization factor of the membrane element $\mathrm{i}$.

$$
\begin{gathered}
\pi_{\mathrm{f}_{\mathrm{i}}}=0.0787 \cdot(273+T) \cdot \Sigma m_{\mathrm{j}} \\
C_{\mathrm{m}_{\mathrm{i}}}=C_{\mathrm{fb}_{\mathrm{i}}} \cdot P F_{\mathrm{i}} \\
C_{\mathrm{fb}_{\mathrm{i}}}=C_{\mathrm{f}_{\mathrm{i}}} \cdot\left(\frac{1+\frac{C_{\mathrm{bi}}}{C_{\mathrm{f}}}}{2}\right) \\
P F_{\mathrm{i}}=\exp \left(0.7 \cdot Y_{\mathrm{i}}\right)
\end{gathered}
$$

$Y_{\mathrm{i}}$ is the element recovery as a fraction. An additional module was developed to calculate $P F_{\mathrm{i}}$ using the Eq. (9)

$$
P F_{\mathrm{i}}=\frac{C_{\mathrm{m}}}{C_{\mathrm{a}}}=\mathrm{e}^{\frac{J}{k}}
$$

where $k$ is the mass transfer coefficient, which is given by the Sherwood number $(S h)$ :

$$
\begin{gathered}
S h=\frac{k \cdot d_{\mathrm{h}}}{D}=a \cdot R e^{b} \cdot S c^{c} \\
R e=\frac{\rho \cdot v \cdot d_{\mathrm{h}}}{\eta} \\
S c=\frac{\eta}{\rho \cdot D}
\end{gathered}
$$

where $d_{\mathrm{h}}(\mathrm{m})$ is the hydraulic diameter, $D$ is the solute diffusivity $\left(\mathrm{m}^{2} \mathrm{~s}^{-1}\right), a, b$ and $c$ are parameters, $S c$ is the Schmidt number, $\rho\left(\mathrm{kg} \mathrm{m}^{-3}\right)$ is the water density, $v$ is the velocity $\left(\mathrm{m} \mathrm{s}^{-1}\right)$ and $\eta\left(\mathrm{kg} \mathrm{m}^{-1} \mathrm{~s}^{-1}\right)$ the dynamic viscosity. Schock and Miquel [34] modeled the parameter $k$ obtaining the Eq. (13). Koutsou et. al. [35] calculated correlations for the $S h$ for different feed spacer geometries (Table 1).

$$
k=0.065 \frac{D}{d_{\mathrm{h}}} \cdot R e^{0.875} \cdot S c^{0.25}
$$


Table $1 S h$ as function of $R e$ and $S c$ for different feed spacer geometries [35].

\begin{tabular}{llll}
\hline & $\beta=90^{\circ}$ & $\beta=105^{\circ}$ & $\beta=120^{\circ}$ \\
\hline$L / d=6$ & $0.14 R e^{0.64} S c^{0.42}$ & $0.08 R e^{0.715} S c^{0.48}$ & $0.073 R e^{0.87} S c^{0.45}$ \\
$L / d=8$ & $0.16 R e^{0.605} S c^{0.42}$ & $0.17 R e^{0.625} S c^{0.42}$ & $0.12 R e^{0.71} S c^{0.43}$ \\
$L / d=12$ & $0.26 R e^{0.57} S c^{0.37}$ & $0.17 R e^{0.64} S c^{0.40}$ & $0.19 R e^{0.645} S c^{0.38}$ \\
\hline
\end{tabular}

- The $T C F$ is calculated as follows [36]:

If $T \geqslant 25^{\circ} \mathrm{C}$ :

$$
T C F=\exp \left[2,640 \cdot\left(\frac{1}{298}-\frac{1}{273+T}\right)\right]
$$

If $T \leqslant 25^{\circ} \mathrm{C}$ :

$$
T C F=\exp \left[3,020 \cdot\left(\frac{1}{298}-\frac{1}{273+T}\right)\right]
$$

- $F F$ (Flow factor) is the coefficient used for considering operating time and fouling. A value of 1 is used to estimate the performance of new membrane elements. This factor was modeled by the long-term predicting model proposed by the authors [30].

Next in the development of the Eq. (1) is the expression of the NDP, which depends on $p_{\mathrm{f}_{\mathrm{i}}}, \Delta p_{\mathrm{fb}_{\mathrm{i}}}, p_{\mathrm{p}_{\mathrm{i}}}, \pi_{\mathrm{m}_{\mathrm{i}}}$ and average osmotic pressure of the permeate $\left(\pi_{\mathrm{p}_{\mathrm{i}}}\right)$ :

$$
N D P=(\Delta p-\Delta \pi)=p_{\mathrm{f}_{\mathrm{i}}}-\frac{\Delta p_{\mathrm{fb}_{\mathrm{i}}}}{2}-p_{\mathrm{p}_{\mathrm{i}}}-\pi_{\mathrm{m}_{\mathrm{i}}}+\pi_{\mathrm{p}_{\mathrm{i}}}
$$

$\Delta p_{\mathrm{fb}}$ depends on two parameters obtained experimentally ( $\mathrm{a}$ and $\mathrm{b}$ ) and average feed-brine flow:

$$
\Delta p_{\mathrm{fb}_{\mathrm{i}}}=\left(\mathrm{a} \cdot\left(\frac{Q_{\mathrm{f}_{\mathrm{i}}}+Q_{\mathrm{r}_{\mathrm{i}}}}{2}\right)^{\mathrm{b}}\right) \cdot 0.07
$$

The Eq. (17) is multiplied by 0.07 due to unit conversion, from psi to $\mathrm{kg} \mathrm{cm}^{-2}$. The proposed software offers other Eqs. to calculate pressure drop in a membrane element. Schock and Miquel [34] proposed the Eq. (18) to obtain the friction factor. Besides, Koutsou et. al. [37] also proposed different correlation for different feed spacer geometries (Table 2). The Eqs obtained in both cases should be multiplied by the parameter $K_{\lambda}$, which was introduced by Geraldes et. al. [15]. This factor takes into consideration additional pressure losses in the feed of the PVs and module fittings.

$$
\lambda=6.23 \cdot R e^{-0.3}
$$

Table 2 Correlation between $\Delta p / \Delta L$ and $R e$ number [37].

\begin{tabular}{llll}
\hline & $\beta=90^{\circ}$ & $\beta=105^{\circ}$ & $\beta=120^{\circ}$ \\
\hline$L / d=6$ & $2.3 R e^{-0.31}$ & $2.2 R e^{-0.23}$ & $3.8 R e^{-0.18}$ \\
$L / d=8$ & $0.8 R e^{-0.19}$ & $0.9 R e^{-0.15}$ & $1.2 R e^{-0.14}$ \\
$L / d=12$ & $1.5 R e^{-0.40}$ & $1.1 R e^{-0.31}$ & $0.7 R e^{-0.19}$ \\
\hline
\end{tabular}

In order to calculate $\pi_{\mathrm{p}_{\mathrm{i}}}$, the average ionic permeability coefficient $(B)$ has to be multiplied by $T C F$ (Eq. (19)), since $B$ depends on temperature. This makes enables the calculation of the ion concentration of the permeate $\left(C_{\mathrm{p}_{\mathrm{j}}}\right)$ :

$$
C_{\mathrm{p}_{\mathrm{j}}}=B_{\mathrm{j}} \cdot P F_{\mathrm{i}} \cdot T C F \cdot \frac{S_{\mathrm{m}}}{Q_{\mathrm{p}_{\mathrm{i}}}} \cdot\left(\frac{C_{\mathrm{f}_{\mathrm{j}}} \cdot\left(1+F C_{\mathrm{i}}\right)}{2}\right)
$$

Once $C_{\mathrm{pj}}$ is obtained, $\pi_{\mathrm{p}_{\mathrm{i}}}$ is calculated according to the Eq. (5). First $Q_{\mathrm{pi}}$ is calculated, and with that, $Y_{\mathrm{i}}$, and then the result is compared to the estimation. Therefore, the function to minimize is the difference between both element recoveries. Knowing the interval of the variable (0-1), the MATLAB ${ }^{\circledR}$ optimizing function $[38,39]$ was used to find minimums on a bounded interval. Fig. 1 shows the procedure of the parameters calculation in the RO elements.

\subsection{Constraints}

The algorithm considers membranes 4 and 8 inch in diameter by 40 inch in length, the most commonly used in brackish water desalination. The experimentation was carried out with a BW30-400 membrane. Dow ${ }^{\circledR}$ membrane manufacturer establish a number of constraints per element regarding maximum recovery $\left(R_{\max }\right)$, maximum permeate flow $\left(Q_{\mathrm{p}-\max }\right)$, minimum rejection flow $\left(Q_{\mathrm{r}-\mathrm{min}}\right)$ and maximum feed flow $\left(Q_{\mathrm{a}-\mathrm{max}}\right)$ all according to the origin and $S D I$ of the feedwater [33]. In this application, these limits can be modified by the user, but always within the limits established by the manufacturer. The proposed program has an additional boundary condition: to achieve the maximum flux recovery without scaling due to the precipitation of sparingly soluble mineral salts (e.g., silica $\left(\mathrm{SiO}_{2}\right)$, calcium carbonate $\left(\mathrm{CaCO}_{3}\right)$, calcium sulphate dihydrate (denoted simply as $\mathrm{CaSO}_{4}$ ), barium 


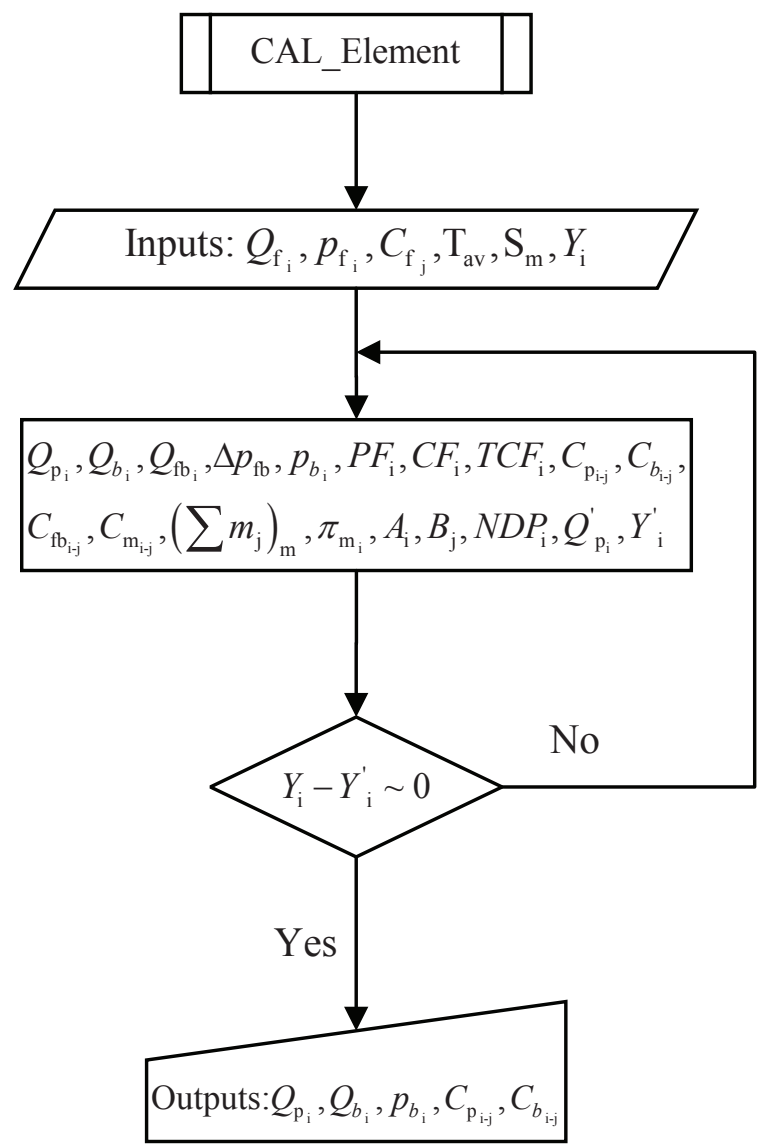

Fig. 1. Calculation of the parameters of the RO elements.

sulphate $\left(\mathrm{BaSO}_{4}\right)$, strontium sulphate $\left(\mathrm{SrSO}_{4}\right)$ and calcium fluoride $\left(\mathrm{CaF}_{2}\right)$ ).

The user can, not only modify, but also add to the manufacturer's constraints, so that the algorithm may stop the calculation of an RO system when the output variables of the element do not comply with the said conditions. These allude to maximum ion concentration of the permeate, or to permeate $T D S$ concentration $\left(T D S_{\mathrm{p}}\right)$. All constraints (including $R_{\max }$ ) are stored in the "Stage" function, where the compliance of the output parameters of the RO elements (CAL_ Element function) is verified to meet the said constraints. If they do, the CAL_Element function is executed again with a new added element (Fig. 1). Otherwise, the number of elements remains fixed, and so does the configuration of the RO system. Fig. 2 shows a diagram for the procedure of the first stage. This will be the same for the second and third stage, where the input parameters will be the output parameters of the previous stage. The maximum number of PV will be limited to the number of PV of the previous stage minus 1, allowing for the possibility of inter-stage pumping.

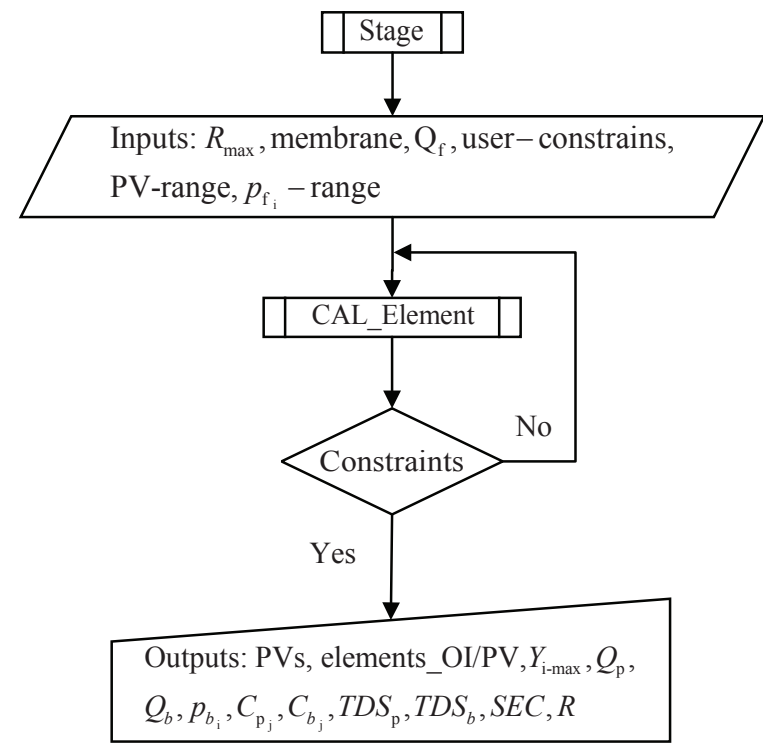

Fig. 2. Calculation of stages of the RO system.

\subsection{Arrangements of considered RO systems}

Systems that have been considered include: threestage, one-step or multi-arrangement (not only the common $3: 2: 1,2: 1$ or $3: 2$ ) RO systems, and from 1 to 8 membrane elements in each PV (Fig. 3). Two-step systems and units with concentrate recirculation have been disregarded due to their rareness. The latter poses a number of difficulties to keep the quality constant in the permeate. Besides, it requires a larger feed tank to homogenize the reject-feed mixture. The algorithm enables the use of a single membrane element throughout the RO system; thus, elements whose diameters are different, or the same but with different active membrane areas, cannot be combined. The number of elements in each PV per stage is the same, though it can differ from stage to stage. Inter-stage pumping at 0.01 and $0.02 \mathrm{MPa}$, and their possible combinations, were taken into consideration.

\subsection{Post-processing. Analysis of results and choosing the RO system}

The calculations of all possible RO systems are followed by the post-processing graphic interface (Fig. 4), in which results are displayed in a table. Each solution (RO system) is a row, and the columns provide 


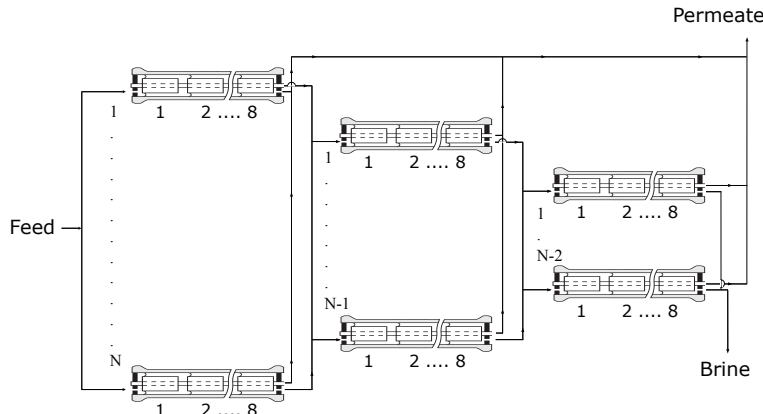

Fig. 3. Arrangenements of considered RO systems.

information regarding: number of stages, number of PV per stage, number of elements in each PV and stage, total number of elements in the system and inter-stage pumping pressure. Additional columns provide information about the operating conditions and the system: feed pressure in each stage, $S E C, Q_{\mathrm{p}},(T D S)_{\mathrm{p}}$, and ion concentration of the permeate. Moreover, information regarding constraints is added, such as maximum recovery, ion concentration and $(T D S)_{\mathrm{p}}$ and parameters established by the manufacturer [33].

The results table is sortable and multi-filterable, which allows the user to sort the results from higher to lower and vice-versa by column (selecting its header). The user may set greater-than, less-than or equal-to conditions for each column to arrive at the desired solution, thus obtaining a sortable intersection of sets according to the parameter of their choosing.

\subsection{Plants description}

In order to validate the design program and its comparison with the manufacturer's software (ROSA), several simulations of plants, built and operating, in the island of Gran Canaria have been carried out. By way of comparison, pumping units were assumed to perform at $100 \%$. The first case was the plant studied by the authors in previous works [29, 30], whose permeate and feedwater inorganic composition is shown in Table 3. This water is characterized by high levels of bicarbonate.

In the other three case studies, the feedwater presents high levels of sulfates, as well as a noticeably higher temperature than the previous one (between $1^{\circ} \mathrm{C}$ and $2^{\circ} \mathrm{C}$ more). Pretreatment was similar in the three plants: cartridge filter of $5 \mu \mathrm{m}$ and antiscalant dosing. These were two-stage RO systems with the same membrane element (BW30-400), whose product water was intended for agricultural irrigation, especially tomato plants. Feedwater temperature for plant 2 (Fig. 5), was $24^{\circ} \mathrm{C}, \mathrm{pH}_{\mathrm{f}}=7.8$ and $\mathrm{pH}_{\mathrm{b}}=8.01$. Its inorganic composition is shown in Table 4.

Table 3 Feedwater inorganic composition of plant 1.

\begin{tabular}{lrrr}
\hline \multirow{2}{*}{ Ion } & \multicolumn{1}{c}{ Feed } & \multicolumn{1}{c}{ Permeate } & Salt rejection \\
\cline { 2 - 4 } & \multicolumn{1}{c}{$\mathrm{mg} / \mathrm{L}$} & \multicolumn{1}{c}{$\mathrm{L} / \mathrm{L}$} & \multicolumn{1}{c}{$\%$} \\
\hline $\mathrm{Ca}^{2+}$ & 135.67 & 1.00 & 99.26 \\
$\mathrm{Mg}^{2}+$ & 304.00 & 1.82 & 99.40 \\
$\mathrm{Na}^{+}$ & $1,642.18$ & 49.43 & 96.99 \\
$\mathrm{~K}^{+}$ & 35.97 & 1.56 & 95.65 \\
$\mathrm{HCO}_{3}^{-}$ & 939.71 & 14.03 & 98.51 \\
$\mathrm{SO}_{4}^{-}$ & 569.21 & 0.48 & 99.92 \\
$\mathrm{NO}_{3}^{-}$ & 257.30 & 26.04 & 89.88 \\
$\mathrm{Cl}^{-}$ & $2,578.65$ & 61.35 & 97.62 \\
$\mathrm{SiO}_{2}$ & 27.50 & 0.20 & 99.27 \\
$\mathrm{Fe}$ & 0.05 & 0.00 & \\
$T D S$ & $6,490.24$ & 155.92 & 97.60 \\
\hline
\end{tabular}

Table 4 Feedwater inorganic composition of plant 2.

\begin{tabular}{lrrr}
\hline \multirow{2}{*}{ Ion } & \multicolumn{1}{c}{ Feed } & \multicolumn{1}{c}{ Permeate } & Salt rejection \\
\cline { 2 - 4 } & \multicolumn{1}{c}{$\mathrm{mg} / \mathrm{L}$} & \multicolumn{1}{c}{$\mathrm{mg} / \mathrm{L}$} & \multicolumn{1}{c}{$\%$} \\
\hline $\mathrm{Ca}^{2+}$ & 395.99 & 3.61 & 99.09 \\
$\mathrm{Mg}^{2+}$ & 428.03 & 3.16 & 99.26 \\
$\mathrm{Na}^{+}$ & 821.66 & 34.03 & 95.86 \\
$\mathrm{~K}^{+}$ & 31.28 & 1.56 & 95.00 \\
$\mathrm{HCO}_{3}^{-}$ & 109.84 & 1.22 & 98.89 \\
$\mathrm{SO}_{4}^{=}$ & 811.79 & 0.48 & 99.94 \\
$\mathrm{NO}_{3}^{-}$ & 99.20 & 8.68 & 91.25 \\
$\mathrm{Cl}^{-}$ & $2,524.75$ & 63.47 & 97.49 \\
$\mathrm{SiO}_{2}$ & 33.70 & 0.27 & 99.20 \\
$\mathrm{Fe}$ & 0.01 & 0.00 & \\
$T D S$ & $5,256.25$ & 116.48 & 97.78 \\
\hline
\end{tabular}

Feedwater temperature for plant 3 (Fig. 6) was also $24^{\circ} \mathrm{C}, \mathrm{pH}_{\mathrm{f}}=7.98$ and $\mathrm{pH}_{\mathrm{b}}=8.10$. Its inorganic composition is shown in Table 5.

For the fourth case (Fig. 7), feedwater temperature was $23{ }^{\circ} \mathrm{C}, \mathrm{pH}_{\mathrm{f}}=7.52$ and $\mathrm{pH}_{\mathrm{b}}=7.88$. Its inorganic composition is shown in Table 6 .

\section{Results and discussion}

\subsection{Algorithm validation}

Tables 7, 8, 9 and 10 compare the initial operating points in four real plants: the actual operating point of 


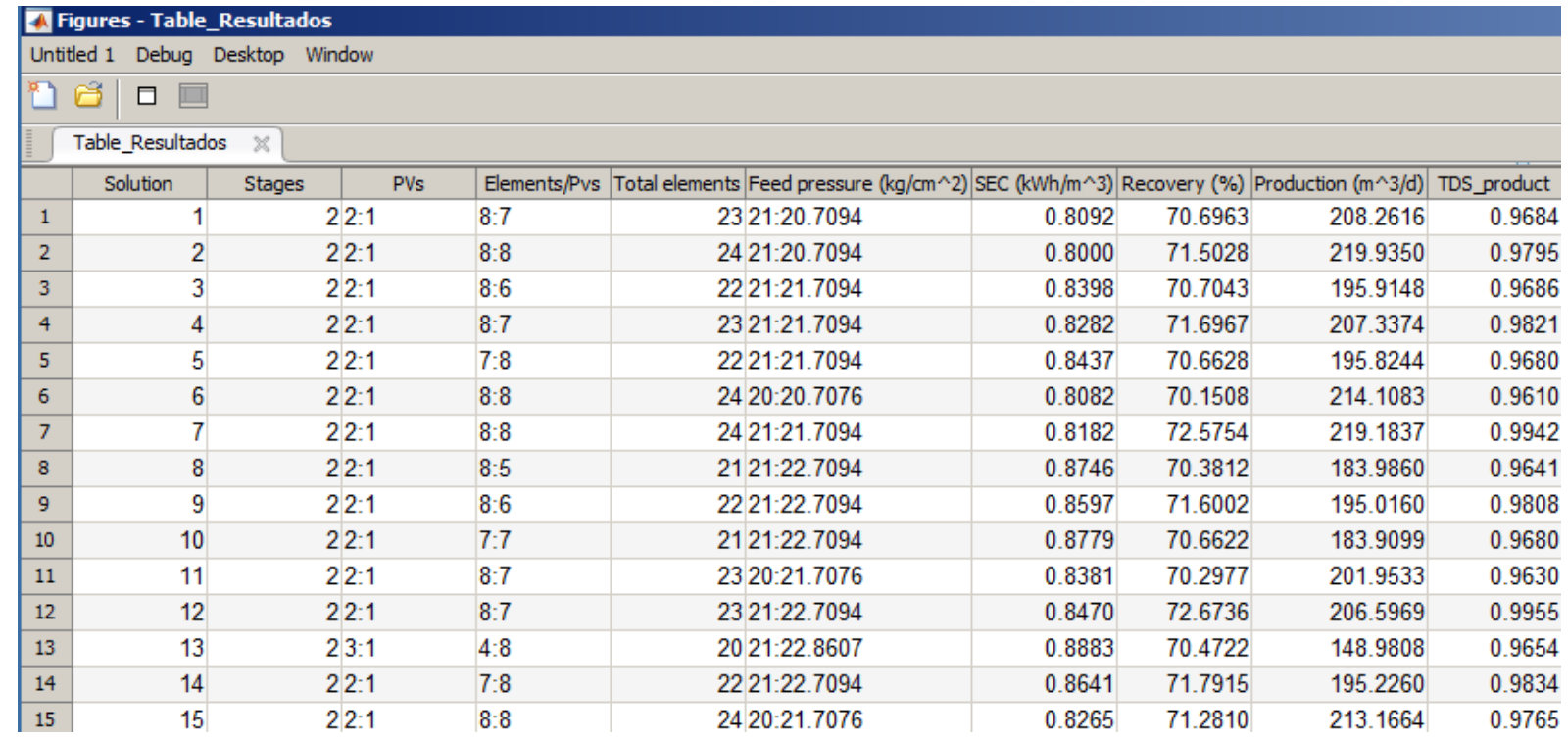

Fig. 4. Post-processing graphic interface.

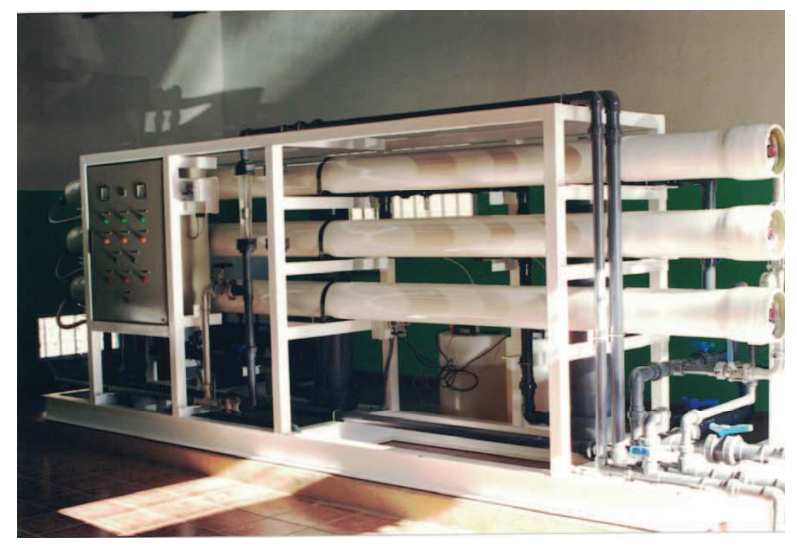

Fig. 5. Desalination plant 2.

the unit, the manufacturer's software (ROSA) estimation, and the estimated by the proposed algorithm. The first row shows the RO system arrangement (number of PVs in the first stage(number of membrane elements per PV in this stage):number of PVs in the second stage(number of membrane elements per PV in this stage)...). These tables show how, under the same conditions of feed and recovery flow, the feed pressure estimated by the algorithm is closer to reality than the estimated by the manufacturer. So is the $T D S_{\mathrm{p}}$ estimation. The estimated $p_{\mathrm{f}}$ is still dissimilar to the real value, but this is due to the use of $a$ and $b$ coefficients proposed by the manufacturer in the Eq. (17) and an estimation of the $A_{0}$ coefficient based on experimental
Table 5 Feedwater inorganic composition of plant 3.

\begin{tabular}{lrrr}
\hline \multirow{2}{*}{ Ion } & \multicolumn{1}{c}{ Feed } & Permeate & Salt rejection \\
\cline { 2 - 4 } & \multicolumn{1}{c}{$\mathrm{mg} / \mathrm{L}$} & \multicolumn{1}{c}{$\mathrm{mg} / \mathrm{L}$} & $\%$ \\
\hline $\mathrm{Ca}^{2+}$ & 182.36 & 1.00 & 99.45 \\
$\mathrm{Mg}^{2+}$ & 203.07 & 2.31 & 98.86 \\
$\mathrm{Na}^{+}$ & 935.69 & 45.52 & 95.14 \\
$\mathrm{~K}^{+}$ & 19.55 & 1.87 & 90.42 \\
$\mathrm{HCO}_{3}^{-}$ & 262.39 & 7.32 & 97.21 \\
$\mathrm{SO}_{4}^{-}$ & $1,047.16$ & 0.90 & 99.91 \\
$\mathrm{NO}_{3}^{-}$ & 117.80 & 13.37 & 88.65 \\
$\mathrm{Cl}^{-}$ & $1,702.08$ & 68.08 & 96.00 \\
$\mathrm{SiO}_{2}$ & 37.10 & 0.26 & 99.30 \\
$\mathrm{Fe}$ & 0.01 & 0.00 & \\
$T D S$ & $4,507.22$ & 140.64 & 96.88 \\
\hline
\end{tabular}

data. The difference between the estimated and actual $T D S_{\mathrm{p}}$ results from using the average $B$ coefficients of plant 1.

It is observable in the said tables that the results obtained by the proposed algorithm offer a solution that is closer to the real operating point of different desalination plants. This is due to the implementation of water and ion permeability coefficients, obtained experimentally for the subject membrane (BW30-400). These, along with the implemented predicting model, can make long-term estimations. Therefore, an analysis of long-term performance, and evaluations on the replacement of membranes and other aspects that contribute to the operation of the plant can be conducted. 


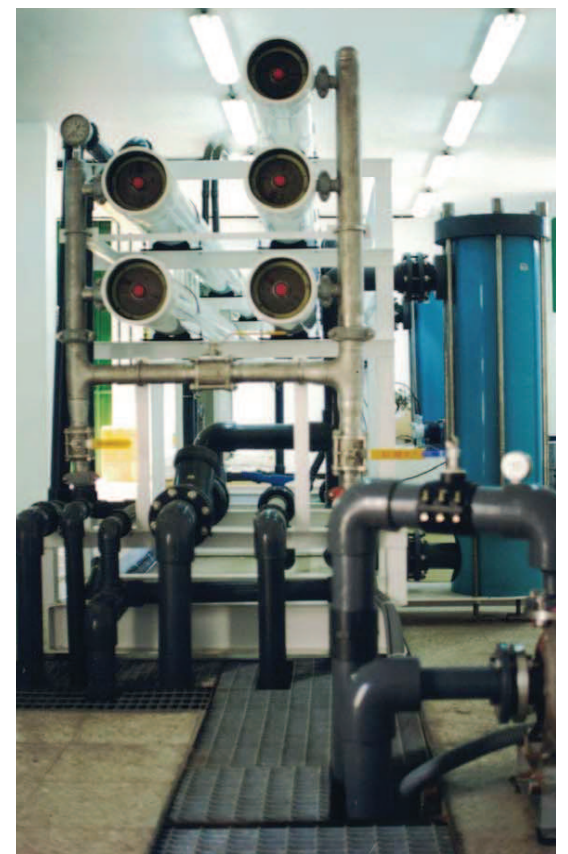

Fig. 6. Desalination plant 3.

\subsection{Alternative RO systems}

This section shows possible solutions for each case with the aim of obtaining a better design of the RO systems, whenever possible, using the same membrane element and establishing the minimum reject flow at $4 \mathrm{~m}^{3} \mathrm{~h}^{-1}$ instead of $3 \mathrm{~m}^{3} \mathrm{~h}^{-1}$ (as established by the manufacturer), since it was a constraint set by the designer.

Alternative RO systems in the first case (Table 11) do not show a significant improvement (the $S E C$ is reduced by $4 \%$ to $5 \%$ ), and there are more membrane elements than in reality. For the second case (Table $11)$, the $S E C$ reductions are slightly larger than in the previous case (3\% to $7 \%$ ), but this implies an increase in the number of membrane elements in the system. In the third case, there are more noticeable differences regarding the $S E C$, where consumption is reduced by $4 \%$ to $17 \%$. Perhaps, the most noteworthy solution is the first with as many membranes as in the real system, and adding an inter-stage booster pump, it can reach a reduction of $13 \%$. The $Q_{\mathrm{f}}$ in the fourth case is clearly superior to the previous ones, which entails more possibilities regarding its design. Table 12 shows some alternative systems, highlighting SEC reductions by $10 \%$. When displaying alternative RO

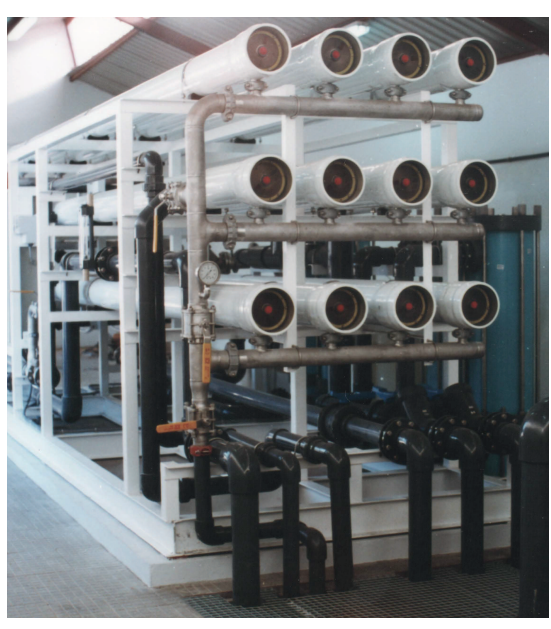

Fig. 7. Desalination plant 4.

Table 6 Feedwater inorganic composition of plant 4.

\begin{tabular}{lrrr}
\hline \multirow{2}{*}{ Ion } & \multicolumn{1}{c}{ Feed } & \multicolumn{1}{c}{ Permeate } & Salt rejection \\
\cline { 2 - 4 } & \multicolumn{1}{c}{$\mathrm{mg} / \mathrm{L}$} & \multicolumn{1}{c}{$\mathrm{mg} / \mathrm{L}$} & \multicolumn{1}{c}{$\%$} \\
\hline $\mathrm{Ca}^{2+}$ & 252.50 & 1.00 & 99.60 \\
$\mathrm{Mg}^{2+}$ & 269.95 & 1.70 & 99.37 \\
$\mathrm{Na}^{+}$ & 1289.74 & 40.92 & 96.83 \\
$\mathrm{~K}^{+}$ & 19.55 & 1.40 & 92.86 \\
$\mathrm{HCO}_{3}^{-}$ & 335.61 & 9.15 & 97.27 \\
$\mathrm{SO}_{4}^{=}$ & 821.40 & 0.59 & 99.93 \\
$\mathrm{NO}_{3}^{-}$ & 341.00 & 26.04 & 92.36 \\
$\mathrm{Cl}^{-}$ & 2244.62 & 50.71 & 97.74 \\
$\mathrm{SiO}_{2}$ & 29.50 & 0.21 & 99.29 \\
$\mathrm{Fe}$ & 0.03 & 0.00 & \\
$T D S$ & $5,603.90$ & 131.73 & 97.65 \\
\hline
\end{tabular}

systems, the same membrane, operating conditions and close to actual number of membranes in the installation have been considered. Generally, the more membranes there are, the lower the $S E C$ will be as low as $0.5 \mathrm{~kW} \mathrm{~h} \mathrm{~m}^{-3}$ with ideal performance of the pump units.

\section{Conclusions}

This work has proposed an algorithm for designing RO systems that will allow the user to obtain them more efficiently than with commercial software supplied by membrane manufacturers. This algorithm was validated using data from four BWRO desalination plants with the same membrane. Implementing permeability coefficients obtained experimentally (knowing the feed spacer geometries) may provide closer-to-actual initial operating points than the ones estimated by manufacturers. This enables the simulation of any generic RO 
Table 7 Comparison plant 1.

\begin{tabular}{cccc}
\hline & Real & ROSA & Program \\
\hline Arrangement & $3(6): 2(6)$ & $3(6): 2(6)$ & $3(6): 2(6)$ \\
Booster & No & No & No \\
$p_{\mathrm{f}}(\mathrm{MPa})$ & 1.41 & 1.31 & 1.37 \\
$Q_{\mathrm{f}}\left(\mathrm{m}^{3} \mathrm{~d}^{-1}\right)$ & 600 & 600 & 600 \\
$R(\%)$ & 58 & 58 & 58 \\
$S E C\left(\mathrm{~kW} \mathrm{~h} \mathrm{~m}^{-3}\right)$ & 0.676 & 0.626 & 0.658 \\
$T D S_{\mathrm{p}}\left(\mathrm{mg} \mathrm{l}^{-1}\right)$ & 155.92 & 203.82 & 130.92 \\
\hline
\end{tabular}

Table 8 Comparison plant 2.

\begin{tabular}{cccc}
\hline & Real & ROSA & Program \\
\hline Arrangement & $2(5): 1(5)$ & $2(5): 1(5)$ & $2(5): 1(5)$ \\
Booster & No & No & No \\
$p_{\mathrm{f}}(\mathrm{MPa})$ & 1.61 & 1.40 & 1.49 \\
$Q_{\mathrm{f}}\left(\mathrm{m}^{3} \mathrm{~d}^{-1}\right)$ & 416.4 & 416.4 & 416.4 \\
$R(\%)$ & 65 & 65 & 65 \\
$S E C\left(\mathrm{~kW} \mathrm{~h} \mathrm{~m}^{-3}\right)$ & 0.688 & 0.596 & 0.637 \\
$T D S_{\mathrm{p}}\left(\mathrm{mg} \mathrm{l}^{-1}\right)$ & 116.48 & 90.27 & 106.43 \\
\hline
\end{tabular}

Table 9 Comparison plant 3 .

\begin{tabular}{cccc}
\hline & Real & ROSA & Program \\
\hline Arrangement & $3(6): 2(6)$ & $3(6): 2(6)$ & $3(6): 2(6)$ \\
Booster & No & No & No \\
$p_{\mathrm{f}}(\mathrm{MPa})$ & 1.59 & 1.37 & 1.44 \\
$Q_{\mathrm{f}}\left(\mathrm{m}^{3} \mathrm{~d}^{-1}\right)$ & 828 & 828 & 828 \\
$R(\%)$ & 65 & 65 & 65 \\
$S E C\left(\mathrm{~kW} \mathrm{~h} \mathrm{~m}^{-3}\right)$ & 0.677 & 0.587 & 0.617 \\
$T D S_{\mathrm{p}}\left(\mathrm{mg} \mathrm{l}^{-1}\right)$ & 140.64 & 96.57 & 116.22 \\
\hline
\end{tabular}

Table 10 Comparison plant 4 .

\begin{tabular}{cccc}
\hline & Real & ROSA & Program \\
\hline Arrangement & $8(6): 4(6)$ & $8(6): 4(6)$ & $8(6): 4(6)$ \\
Booster & No & No & No \\
$p_{\mathrm{f}}(\mathrm{MPa})$ & 1.64 & 1.47 & 1.57 \\
$Q_{\mathrm{f}}\left(\mathrm{m}^{3} \mathrm{~d}^{-1}\right)$ & 2,154 & 2,154 & 2,154 \\
$R(\%)$ & 60 & 60 & 60 \\
$S E C\left(\mathrm{~kW} \mathrm{~h} \mathrm{~m}^{-3}\right)$ & 0.756 & 0.683 & 0.726 \\
$T D S_{\mathrm{p}}\left(\mathrm{mg} \mathrm{l}^{-1}\right)$ & 131.37 & 144.03 & 138.75 \\
\hline
\end{tabular}

system with spiral-wound modules. Moreover, with this computational tool the user may conservatively modify the current constraints, or add others inexistent in the software of membrane manufacturers. Thus, the user has more flexibility to design BWRO systems than with software supplied by membrane manufacturers.

\section{References}

\section{References}

[1] S. A. Aani, C. J. Wright, M. A. Atieh, N. Hilal, Engineering nanocomposite membranes: Addressing current challenges and future opportunities, Desalination 401 (2017) 1 - 15, 50th anniversary of Desalination. doi:https://doi.org/10.1016/j.desal.2016.08.001. URL http://www.sciencedirect.com/science/ article/pii/S001191641630995X

[2] P. Cay-Durgun, C. McCloskey, J. Konecny, A. Khosravi, M. L. Lind, Evaluation of thin film nanocomposite reverse osmosis membranes for long-term brackish water desalination performance, Desalination 404 (2017) 304 - 312. doi : http: //dx.doi.org/10.1016/j.desal.2016.10.014.

URL //www.sciencedirect.com/science/article/ $\mathrm{pii/S0011916416305756}$

[3] W. Choi, J. Choi, J. Bang, J.-H. Lee, Layer-by-layer assembly of graphene oxide nanosheets on polyamide membranes for durable reverse-osmosis applications, ACS Applied Materials \& Interfaces 5 (23) (2013) 12510-12519, pMID: 24219033. arXiv:http://dx.doi.org/10.1021/ am403790s, doi:10.1021/am403790s. URL http://dx.doi.org/10.1021/am403790s

[4] H.-G. Park, S.-G. Cho, K.-J. Kim, Y.-N. Kwon, Effect of feed spacer thickness on the fouling behavior in reverse osmosis process a pilot scale study, Desalination 379 (2016) 155 - 163. doi:http://dx.doi.org/10.1016/j.desal.2015.11. 011.

URL //www.sciencedirect.com/science/article/ pii/S0011916415301132

[5] A. Radu, M. van Steen, J. Vrouwenvelder, M. van Loosdrecht, C. Picioreanu, Spacer geometry and particle deposition in spiral wound membrane feed channels, Water Research 64 (2014) 160 - 176. doi:http: //dx.doi.org/10.1016/j. watres.2014.06.040.

URL //www.sciencedirect.com/science/article/ pii/S0043135414004850

[6] C. Koutsou, A. Karabelas, M. Kostoglou, Membrane desalination under constant water recovery the effect of module design parameters on system performance, Separation and Purification Technology 147 (2015) 90 - 113. doi:http: //dx.doi.org/10.1016/j.seppur.2015.04.012.

URL //www.sciencedirect.com/science/article/ pii/S1383586615002361

[7] X. Liu, W. Li, T. H. Chong, A. G. Fane, Effects of spacer orientations on the cake formation during membrane fouling: Quantitative analysis based on $3 \mathrm{~d}\{\mathrm{OCT}\}$ imaging, Water Research 110 (2017) 1 - 14 . doi:https: //doi.org/10.1016/j.watres.2016.12.002. URL http://www.sciencedirect.com/science/ article/pii/S0043135416309368

[8] L. X. Gao, A. Rahardianto, H. Gu, P. D. Christofides, Y. Cohen, Novel design and operational control of integrated ultrafiltration reverse osmosis system with $\{\mathrm{RO}\}$ concentrate backwash, Desalination 382 (2016) 43 - 52. doi:http: //dx.doi.org/10.1016/j.desal.2015.12.022.

URL //www.sciencedirect.com/science/article/ pii/S0011916415301569

[9] S. Lin, M. Elimelech, Kinetics and energetics trade-off in reverse osmosis desalination with different configurations, Desalination 401 (2017) $42-52$, 50th anniversary of Desalination. doi:http://dx.doi .org/10.1016/j.desal.2016.09. 008. 
Table 11 Alternative RO systems for plants 1 and 2.

\begin{tabular}{|c|c|c|c|c|c|c|c|c|c|c|}
\hline & \multicolumn{5}{|c|}{ Plant 1} & \multicolumn{5}{|c|}{ Plant 2} \\
\hline Arrangement & $3(8): 2(8)$ & $3(7): 2(8)$ & $3(8): 2(7)$ & $3(7): 2(8): 1(2)$ & $4(3): 3(5): 2(7)$ & $2(6): 1(8)$ & $2(6): 1(7)$ & $2(5): 1(8)$ & $2(5): 1(8)$ & $2(5): 1(7)$ \\
\hline Booster (MPa) & 0.01 & No & 0.01 & No & $0 / 0.02$ & 0.02 & 0.02 & No & 0.01 & No \\
\hline$p_{\mathrm{f}}(\mathrm{MPa})$ & 1.26 & 1.32 & 1.27 & 1.31 & 1.19 & 1.26 & 1.28 & 1.42 & 1.37 & 1.44 \\
\hline$Q_{\mathrm{f}}\left(\mathrm{m}^{3} \mathrm{~d}^{-1}\right)$ & 600 & 600 & 600 & 600 & 600 & 416.4 & 416.4 & 416.4 & 416.4 & 416.4 \\
\hline$R(\%)$ & 58 & 58 & 58 & 58 & 58 & 65 & 65 & 65 & 65 & 65 \\
\hline$S E C\left(\mathrm{~kW} \mathrm{~h} \mathrm{~m}^{-3}\right)$ & 0.624 & 0.625 & 0.632 & 0.627 & 0.628 & 0.595 & 0.604 & 0.607 & 0.614 & 0.615 \\
\hline$T D S_{\mathrm{p}}\left(\mathrm{mg} \mathrm{l}^{-1}\right)$ & 164.37 & 153.16 & 157.13 & 247.13 & 256.79 & 139.79 & 131.42 & 130.55 & 127.904 & 122.024 \\
\hline
\end{tabular}

Table 12 Alternative RO systems for plants 3 and 4.

\begin{tabular}{|c|c|c|c|c|c|c|c|c|c|c|}
\hline & \multicolumn{5}{|c|}{ Plant 3} & \multicolumn{5}{|c|}{ Plant 4} \\
\hline Arrangement & $4(6): 2(8)$ & $4(5): 2(7)$ & $4(5): 2(6)$ & $4(4): 2(7)$ & $5(3): 3(7): 2(5)$ & $12(4): 8(5)$ & 13(3):7(6) & $13(2): 8(6)$ & 11(4):7(4) & $11(4): 8(3)$ \\
\hline Booster (MPa) & 0.01 & No & 0.01 & No & No & 0.01 & 0.01 & No & No & No \\
\hline$p_{\mathrm{f}}(\mathrm{MPa})$ & 1.20 & 1.28 & 1.28 & 1.38 & 1.2 & 1.27 & 1.31 & 1.47 & 1.47 & 1.47 \\
\hline$Q_{\mathrm{f}}$ & 828 & 828 & 828 & 828 & 828 & 2154 & 2154 & 2154 & 2154 & 2154 \\
\hline$R(\%)$ & 65 & 65 & 65 & 65 & 65 & 60 & 60 & 60 & 60 & 60 \\
\hline$S E C\left(\mathrm{~kW} \mathrm{~h} \mathrm{~m}^{-3}\right)$ & 0.535 & 0.561 & 0.577 & 0.592 & 0.512 & 0.622 & 0.649 & 0.664 & 0.673 & 0.689 \\
\hline$T D S_{\mathrm{p}}\left(\mathrm{mg} \mathrm{l}^{-1}\right)$ & 133.14 & 113.98 & 104.65 & 100.17 & 270.89 & 220.1922 & 178.9668 & 170.6448 & 177.8864 & 185.1864 \\
\hline
\end{tabular}

URL //www.sciencedirect.com/science/article/ pii/S0011916416312656

[10] J. R. Werber, A. Deshmukh, M. Elimelech, Can batch or semi-batch processes save energy in reverse-osmosis desalination?, Desalination 402 (2017) 109 - 122. doi:http: //dx.doi.org/10.1016/j.desal.2016.09.028.

URL //www.sciencedirect.com/science/article/ pii/S0011916416306312

[11] J. Zhang, K. Northcott, M. Duke, P. Scales, S. R. Gray, Influence of pre-treatment combinations on $\{\mathrm{RO}\}$ membrane fouling, Desalination 393 (2016) 120 - 126, fouling and Scaling in Desalination. doi:https: //doi.org/10.1016/j.desal.2016.02.020.

URL http://www.sciencedirect.com/science/ article/pii/S0011916416300583

[12] A. Villafafila, I. Mujtaba, Fresh water by reverse osmosis based desalination: simulation and optimisation, Desalination 155 (1) (2003) 1 - 13. doi:http: //dx.doi.org/10.1016/S0011-9164(03)00234-0.

URL http://www.sciencedirect.com/science/ article/pii/S0011916403002340

[13] M. Barello, D. Manca, R. Patel, I. Mujtaba, Operation and modeling of ro desalination process in batch mode, Computers \& Chemical Engineering 83 (2015) 139 - 156, 24th European Symposium on Computer Aided Process Engineering(ESCAPE). doi:http: //dx.doi.org/10.1016/j.compchemeng. 2015.05.022. URL http://www.sciencedirect.com/science/ article/pii/S0098135415002033

[14] M. G. Marcovecchio, P. A. Aguirre, N. J. Scenna, Desalination and the environment global optimal design of reverse osmosis networks for seawater desalination: modeling and algorithm, Desalination 184 (1) (2005) 259 - 271. doi : http: //dx.doi.org/10.1016/j.desal.2005.03.056.

URL http://www.sciencedirect.com/science/ article/pii/S0011916405005710

[15] V. Geraldes, N. E. Pereira, M. N. de Pinho, Simulation and optimization of medium-sized seawater reverse osmosis processes with spiral-wound modules, Industrial \& Engineering Chemistry Research 44 (6) (2005) 1897-1905. arXiv:http://dx. doi.org/10.1021/ie049357s, doi:10.1021/ie049357s. URL http://dx.doi.org/10.1021/ie049357s

[16] C. Guria, P. K. Bhattacharya, S. K. Gupta, Multi-objective optimization of reverse osmosis desalination units using different adaptations of the non-dominated sorting genetic algorithm (nsga), Computers \& Chemical Engineering 29 (9) (2005) 1977 - 1995. doi:http: //dx.doi.org/10.1016/j.compchemeng.2005.05.002.

URL http://www.sciencedirect.com/science/ article/pii/S0098135405001298

[17] Y.-Y. Lu, Y.-D. Hu, X.-L. Zhang, L.-Y. Wu, Q.-Z. Liu, Optimum design of reverse osmosis system under different feed concentration and product specification, Journal of Membrane Science 287 (2) (2007) 219 - 229. doi:http: //dx.doi.org/10.1016/j.memsci.2006.10.037. URL http://www.sciencedirect.com/science/ article/pii/S0376738806007071

[18] F. Vince, F. Marechal, E. Aoustin, P. Bréant, Multiobjective optimization of ro desalination plants, Desalination 222 (1) (2008) 96 - 118. doi:http: //dx.doi.org/10.1016/j.desal.2007.02.064.

URL http://www.sciencedirect.com/science/ article/pii/S0011916407007606

[19] K. M. Sassi, I. M. Mujtaba, Optimal design and operation of reverse osmosis desalination process with membrane fouling, Chemical Engineering Journal 171 (2) (2011) 582 - 593. doi:http://dx.doi.org/10.1016/j.cej.2011.04.034. URL http://www.sciencedirect.com/science/ article/pii/S1385894711004864

[20] A. Abbas, N. Al-Bastaki, Performance decline in brackish water film tec spiral wound ro membranes, Desalination 136 (1) (2001) 281 - 286. doi:http: //dx.doi.org/10.1016/S0011-9164(01)00191-6.

URL http://www.sciencedirect.com/science/ article/pii/S0011916401001916

[21] Y. Du, L. Xie, Y. Wang, Y. Xu, S. Wang, Optimization of reverse osmosis networks with spiral-wound modules, Industrial \& Engineering Chemistry Research 51 (36) (2012) 1176411777. arXiv:http://dx.doi.org/10.1021/ie300650b, doi:10.1021/ie300650b.

URL http://dx.doi.org/10.1021/ie300650b

[22] Y. Du, L. Xie, J. Liu, Y. Wang, Y. Xu, S. Wang, Multiobjective optimization of reverse osmosis networks by lexicographic optimization and augmented epsilon constraint method, Desalination 333 (1) (2014) 66 - 81. doi:http: //dx.doi.org/10.1016/j.desal.2013.10.028. 
URL http://www.sciencedirect.com/science/ article/pii/S0011916413005109

[23] Y. Du, L. Xie, Y. Liu, S. Zhang, Y. Xu, Optimization of reverse osmosis networks with split partial second pass design, Desalination 365 (2015) 365 - 380. doi:http: //dx.doi.org/10.1016/j.desal.2015.03.019.

URL http://www.sciencedirect.com/science/ article/pii/S0011916415001861

[24] H. Kotb, E. Amer, K. Ibrahim, On the optimization of ro (reverse osmosis) system arrangements and their operating conditions, Energy 103 (2016) 127 - 150. doi:http: //dx.doi.org/10.1016/j.energy.2016.02.162.

URL http://www.sciencedirect.com/science/ article/pii/S0360544216302249

[25] A. Altaee, Computational model for estimating reverse osmosis system design and performance: Part-one binary feed solution, Desalination 291 (2012) 101 - 105. doi:http: //dx.doi.org/10.1016/j.desal.2012.01.028. URL http://www.sciencedirect.com/science/ article/pii/S0011916412000793

[26] E. R. Saavedra, A. G. Gotor, S. O. P. Báez, A. R. Martín, A. Ruiz-García, A. C. González, A design method of the ro system in reverse osmosis brackish water desalination plants (procedure), Desalination and Water Treatment 51 (25-27) (2013) 4790-4799. arXiv:http: //dx.doi.org/10.1080/19443994.2013.774136, doi:10.1080/19443994.2013.774136.

URL http://dx.doi.org/10.1080/19443994.2013. 774136

[27] E. Ruiz-Saavedra, A. Ruiz-García, A. Ramos-Martín, A design method of the ro system in reverse osmosis brackish water desalination plants (calculations and simulations), Desalination and Water Treatment 55 (9) (2015) 2562-2572. arXiv: http://dx.doi.org/10.1080/19443994.2014.939489, doi:10.1080/19443994.2014.939489.

URL http://dx.doi.org/10.1080/19443994.2014. 939489

[28] J.-S. Choi, J.-T. Kim, Modeling of full-scale reverse osmosis desalination system: Influence of operational parameters, Journal of Industrial and Engineering Chemistry 21 (2015) 261 - 268. doi:http://dx.doi.org/10.1016/j.jiec. 2014. 02.033 .

URL http://www.sciencedirect.com/science/ article/pii/S1226086X1400118X

[29] A. Ruiz-García, E. Ruiz-Saavedra, 80,000 h operational experience and performance analysis of a brackish water reverse osmosis desalination plant. assessment of membrane replacement cost, Desalination 375 (2015) 81 - 88. doi : http: //dx.doi.org/10.1016/j.desal.2015.07.022.

URL http://www.sciencedirect.com/science/ article/pii/S0011916415300308

[30] A. Ruiz-Garca, I. Nuez, Long-term performance decline in a brackish water reverse osmosis desalination plant. predictive model for the water permeability coefficient, Desalination 397 (2016) 101 - 107. doi:http: //dx.doi.org/10.1016/j.desal.2016.06.027.

URL //wWw.sciencedirect.com/science/article/ pii/S0011916416307093

[31] J. Wijmans, R. Baker, The solution-diffusion model: a review, Journal of Membrane Science 107 (1) (1995) 1-21. doi : http: //dx.doi.org/10.1016/0376-7388(95)00102-I.

URL http://www.sciencedirect.com/science/ article/pii/037673889500102I

[32] M. Al-Obaidi, C. Kara-Zaitri, I. Mujtaba, Scope and limitations of the irreversible thermodynamics and the solution diffusion models for the separation of binary and multicomponent systems in reverse osmosis process, Computers \& Chemical Engineering 100 (2017) 48 - 79. doi : https: //doi.org/10.1016/j. compchemeng.2017.02.001.

URL http://www.sciencedirect.com/science/ article/pii/S0098135417300571

[33] D. Water, P. Solutions, Filmtec Reverse Osmosis Membranes Technical Manual, Dow Water and Process Solutions, 2005.

[34] G. Schock, A. Miquel, Mass transfer and pressure loss in spiral wound modules, Desalination 64 (1987) 339-352. doi : http: //dx.doi.org/10.1016/0011-9164(87)90107-X.

URL http://www.sciencedirect.com/science/ article/pii/001191648790107X

[35] C. Koutsou, S. Yiantsios, A. Karabelas, A numerical and experimental study of mass transfer in spacer-filled channels: Effects of spacer geometrical characteristics and schmidt number, Journal of Membrane Science 326 (1) (2009) 234 - 251. doi : http://dx.doi.org/10.1016/j.memsci.2008.10.007. URL http://www.sciencedirect.com/science/ article/pii/S0376738808008946

[36] A. Marsh, P. Eriksson, Projecting ro desalination system performance with filmtec spiral-wound elements, in: Proc. of the Seminar on Membrane Processes, 1988.

[37] C. Koutsou, S. Yiantsios, A. Karabelas, Direct numerical simulation of flow in spacer-filled channels: Effect of spacer geometrical characteristics, Journal of Membrane Science 291 (1) (2007) 53 - 69. doi:http: //dx.doi.org/10.1016/j.memsci.2006.12.032. URL http://www.sciencedirect.com/science/ article/pii/S0376738806008532

[38] R. P. Brent, Algorithms for minimization without derivatives, Courier Corporation, 2013.

[39] G. E. Forsythe, M. A. Malcolm, C. B. Moler, Computer methods for mathematical computations, Prentice-Hall, 1977 